\title{
Identification of a novel potassium channel (GiK) as a potential drug target in Giardia lamblia: Computational descriptions of binding sites
}

\author{
Lissethe Palomo-Ligas ${ }^{1}$, Filiberto Gutiérrez-Gutiérrez ${ }^{2}$, Verónica Yadira Ochoa-Maganda ${ }^{1}$, Rafael Cortés- \\ Zárate $^{3}$, Claudia Lisette Charles-Niño ${ }^{3}$, Araceli Castillo-Romero ${ }^{\text {Corresp. } 3}$ \\ 1 Departamento de Fisiología, Centro Universitario de Ciencias de la Salud, Universidad de Guadalajara, Guadalajara, Jalisco, Mexico \\ 3 Departamento de Microbiología y Patología, Centro Universitario de Ciencias de la Salud, Universidad de Guadalajara, Guadalajara, Jalisco, Mexico \\ Corresponding Author: Araceli Castillo-Romero \\ Email address: araceli.castillo@cucs.udg.mx
}

Background. The protozoan Giardia lamblia is the causal agent of giardiasis, one of the main diarrheal infections worldwide. Drug resistance to common antigiardial agents and incidence of treatment failures have increased in recent years. Therefore, the search for new molecular targets for drugs against Giardia infection is essential. In protozoa, ionic channels have roles in their life cycle, growth, and stress response. Thus, they are promising targets for drug design. The strategy of ligand-protein docking has demonstrated a great potential in the discovery of new targets and structure-based drug design studies. Methods. In this work, we identify and characterize a new potassium channel, GiK, in the genome of Giardia lamblia. Characterization was performed in silico. Because its crystallographic structure remains unresolved, homology modeling was used to construct, the three-dimensional model for the pore domain of GiK. The docking virtual screening approach was employed to determine whether GiK is a good target for potassium channel blockers. Results. The GiK sequence showed $24-50 \%$ identity and 50 $90 \%$ positivity with 21 different types of potassium channels. The quality assessment and validation parameters indicated the reliability of the modeled structure of GiK. We identified one hundred ten potassium channel blockers exhibiting high affinity toward GiK. Thirty-nine of these drugs bind in three specific regions. Discussion. The GiK pore signature sequence is related to the small conductance calcium-activated potassium channels (SKCa). The predicted binding of one hundred ten potassium blockers to GiK makes this protein an attractive target for biological testing to evaluate its role in the life cycle of Giardia lamblia and potential candidate for the design of novel antigiardial drugs. 
1 Identification of a novel potassium channel (GiK) as a potential drug target in

2 Giardia lamblia: Computational descriptions of binding sites.

3 Lissethe Palomo-Ligas ${ }^{1}$, Filiberto Gutiérrez-Gutiérrez², Verónica Yadira Ochoa-

4 Maganda ${ }^{1}$, Rafael Cortés-Zárate ${ }^{3}$, Claudia Lisette Charles-Niño ${ }^{3}$, Araceli Castillo-

5 Romero $^{3}$

6 'Departamento de Fisiología, Centro Universitario de Ciencias de la Salud, Universidad

7 de Guadalajara, Guadalajara Jalisco, México

8 2Departamento de Química, Centro Universitario de Ciencias Exactas e Ingenierías,

9 Universidad de Guadalajara, Guadalajara, Jalisco, México

10 32Departamento de Microbiología y Patología, Centro Universitario de Ciencias de la

11 Salud, Universidad de Guadalajara, Guadalajara Jalisco, México

12 Corresponding author

13 Araceli Castillo-Romero 3

14 E-mail: araceli.castillo@cucs.udg.mx 


\section{Abstract}

17 Background. The protozoan Giardia lamblia is the causal agent of giardiasis, one of 18 the main diarrheal infections worldwide. Drug resistance to common antigiardial agents

19

20

21

22

23

24

25

26

27

28

29

30

31

32

33

34

35

36

37

38

39

40

41

42

43

44

45 and incidence of treatment failures have increased in recent years. Therefore, the search for new molecular targets for drugs against Giardia infection is essential. In protozoa, ionic channels have roles in their life cycle, growth, and stress response. Thus, they are promising targets for drug design. The strategy of ligand-protein docking has demonstrated a great potential in the discovery of new targets and structure-based drug design studies.

Methods. In this work, we identify and characterize a new potassium channel, GiK, in the genome of Giardia lamblia. Characterization was performed in silico. Because its crystallographic structure remains unresolved, homology modeling was used to construct, the three-dimensional model for the pore domain of GiK. The docking virtual screening approach was employed to determine whether GiK is a good target for potassium channel blockers.

Results. The GiK sequence showed $24-50 \%$ identity and $50-90 \%$ positivity with 21 different types of potassium channels. The quality assessment and validation parameters indicated the reliability of the modeled structure of GiK. We identified one hundred ten potassium channel blockers exhibiting high affinity toward GiK. Thirty-nine of these drugs bind in three specific regions.

Discussion. The GiK pore signature sequence is related to the small conductance calcium-activated potassium channels (SKCa). The predicted binding of one hundred ten potassium blockers to GiK makes this protein an attractive target for biological testing to evaluate its role in the life cycle of Giardia lamblia and potential candidate for the design of novel antigiardial drugs.

\section{Introduction}

3 Giardia lamblia is the causal agent of giardiasis, a prolonged diarrheal disease. The 4 standard compounds used against Giardia lamblia are 5-nitroimidazoles. However, these compounds present side effects associated with residual toxicity in the host. 
46 Dose-dependent side effects include leukopenia, headache, vertigo, nausea, insomnia, 47 irritability, metallic taste, and CNS toxicity (Ansell et al. 2015; Escobedo \& Cimerman 48 2007; Tejman-Yarden \& Eckmann 2011; Watkins \& Eckmann 2014). In addition, reports 49 of resistant strains and nitroimidazole-refractory disease are of considerable concern. 50 Reduced efficacy has been described even with higher drug doses (Carter et al. 2018; 51 Leitsch 2015). For these reasons, there is a significant need for identification of new 52 anti-Giardia drugs and drug targets. Ionic channels are pore-forming proteins that allow 53 the passage of specific ions across the membrane, regulating different physiological 54 processes (Subramanyam \& Colecraft 2015). Because of their biophysical behavior and 55 56 participation in different human pathologies, ionic channels are attractive targets for drug design (Bagal et al. 2013). Potassium channels are the most diverse and ubiquitous group of ion channels. They are divided into four main families on the basis of their biophysical and structural properties: voltage-gated $\mathrm{K}^{+}$channels, calciumactivated $\mathrm{K}^{+}$channels $\left(\mathrm{K}_{\mathrm{Ca}}\right)$, inward-rectifier $\mathrm{K}^{+}$channels and two-pore-domain $\mathrm{K}^{+}$ channels $\left(K_{2 P}\right)$ (Wulff et al. 2009). In both electrically excitable and non-excitable cells, potassium channels regulate multiple cellular functions including cell volume, proliferation, differentiation, and motility (Grunnet et al. 2002; Pchelintseva \& Djamgoz 2018; Schwab et al. 2008; Urrego et al. 2014).

Recently, several studies have reported identification and characterization of $\mathrm{K}^{+}$ channels in pathogenic protozoa. In Plasmodium falciparum and Trypanosoma cruzi, these channels are expressed in different stages of the parasite life cycle. They are essential for growth and play a significant role in parasite response to environmental stresses (Ellekvist et al. 2004; Jimenez \& Docampo 2012; Waller et al. 2008). A heterodimeric $\mathrm{Ca}^{2+}$-activated potassium channel was identified in Trypanosoma brucei.

71 This identification was accomplished by profile searches of the predicted parasite 72 proteome against the conserved loop of cation channels. The channel identified was 73 found to be essential for the bloodstream form parasites (Steinmann et al. 2015). The 74 National Center for Advancing Translational Sciences Small Molecule Repository was 75 screened. In this screening, fluticasone propionate was identified as a potential good inhibitor of $T$. brucei potassium channels. Experiments confirmed fluticasone propionate 
77 as a candidate drug targeting T. brucei (IC50 of $0.6 \mu \mathrm{M})$ (Schmidt et al. 2018). Biaguini 78 and coworkers showed that $\mathrm{K}^{+}$causes an important depolarization of the membrane in 79 Giardia lamblia (Biagini et al. 2000). Results of others studies, report that $\mathrm{K}^{+}$plays an 80 important role as an osmolyte regulating Giardia cell volume (Maroulis et al. 2000). 81 Xenopus oocytes were injected with mRNA isolated from trophozoites of G. lamblia, 82 subsequent electrophysiology experiments revealed potassium currents (Ponce et al. 83 2013). By genome analysis and a bioinformatic approach, Prole and Marrion identified a 84 putative potassium channel in Giardia lamblia assemblage $E$ (Prole \& Marrion 2012).

85 However, the structural characterization of ionic channels in this protozoan is limited. 86 Consequently, the potential of these channels to serve as a drug targets is poorly 87 understood.

In recent years, in silico strategies have been used frequently to estimate protein 90 function, for the discovery of new target molecules and for structure-based drug design 91 studies (Chen \& Chen 2008). This work describes computational approaches to determine structural biology of a putative Giardia potassium channel, GiK. Further, this work evaluates the potential of this channel to serve as a novel target. . A closed-state pore domain of GiK homology model was constructed. This construction was accomplished using a high conductance calcium-activated potassium channel from Aplysia californica (PDB ID: 5TJI) as a template. Our docking and virtual screening approach identified one hundred ten potassium channel blockers exhibiting high free energy of binding to GiK, thirty-nine of these drugs bind in the pore region of the channel. The drugs interact mainly with sites in three specific regions: S5, S2-S4 and Cterminal. These findings support the conclusion that this protein is an attractive target for biological testing to reveal its role in the life cycle of Giardia lamblia and a potential candidate for the design of novel antigiardial drugs.

\section{Materials and Methods}


1072.1 In silico putative potassium channel identification in Giardia

108 To identify homologous sequences in Giardia lamblia, fifty-one potassium channel

109 sequences from genomes of different species, deposited in the NCBI protein database

110 (http://www.ncbi.nlm.nih.gov/protein), were compared by BLAST algorithm with the

111 Giardia genome database (http://giardiadb.org/giardiadb/).

112 The amino acid composition, physicochemical properties, solvation and protein binding

113 sites of the resulting sequence (GiK) (Accession number XP_001709490) were

114 analyzed using PROTPARAM ((http://expasy.org/tools/) and PredictProtein (Yachdav et

115 al. 2014). We applied PONDR (Predictor of Natural Disordered Regions) (Obradovic et

116 al. 2003) to predict disorder regions. Highly conserved residues were identified by

117 consensus results of NCBI Conserved domains (Marchler-Bauer et al. 2017), Motif

118 Search (http://www.genome.jp/tools/motif/), InterProScan tool (Jones et al. 2014), Block

119 Searcher (Henikoff \& Henikoff 1994), and ExPASy PROSITE (Sigrist et al. 2013).

120 Consensus results of the Constrained Consensus TOPology prediction server (Tusnady

121 \& Simon 1998; Tusnady \& Simon 2001) and PredictProtein (Yachdav et al. 2014)

122 servers were used for the prediction of transmembrane domains.

123

$124 \quad 2.2$ Prediction of the potassium blockers binding sites on GiK

125 2.2.1 Homology model and refinement

126 The crystal structure of GiK is not available. Therefore, three-dimensional (3D) models

127 of the pore region (1-500 aa) were produced using I-TASSER (Iterative Threading

128 ASSEmbly Refinement) (Roy et al. 2010; Yang et al. 2015; Zhang 2008), RaptorX (Ma

129 et al. 2012; Ma et al. 2013; Peng \& Xu 2010), Phyre2 (Protein Homology/analogY

130 Recognition Engine V 2.0) (Kelley et al. 2015), SWISS- MODEL (Arnold et al. 2006;

131 Biasini et al. 2014; Bordoli et al. 2008), and Modeller 9.18 (Fiser et al. 2000; Martí-

132 Renom et al. 2000; Šali \& Blundell 1993; Webb \& Sali 2002). First, we searched the

133 PDB (Berman et al. 2007) for known protein structures using the GiK sequence as

134 query. We also searched for suitable templates in the SWISS-MODEL Template library.

135 Next, a multiple alignment of the GiK sequence (UniProtKB accession: A8B451) to the

136 main template structures was calculated, by MultAlin software (Corpet 1988).

137 Optimization of the hydrogen bonding network and the atomic level energy minimization 
138 of the 3D-GiK models generated were performed using the What If Web Interface 139 (Chinea et al. 1995) and the 3D Refine protein structure refinement server

140 (Bhattacharya \& Cheng 2013; Bhattacharya et al. 2016). The global structural quality of 141 predicted models was validated by RAMPAGE (Ramachandran Plot Analysis) (Lovell et 142 al. 2003), QMEAN (Qualitative Model Energy Analysis) (Benkert et al. 2008), Verify 3D 143 (Bowie et al. 1991; Luthy et al. 1992), ERRAT (Colovos \& Yeates 1993) and ProSA-web 144 (Wiederstein \& Sippl 2007). The 3D-GiK model with the best scoring was selected for 145 refinement using UCSF CHIMERA v1.11.1 (Pettersen et al. 2004). We used 100 steps 146 of conjugate gradient minimization. The QMEANBrane tool was used to assess the local 147 quality of the 3D-GiK membrane protein model (Studer et al. 2014). To confirm the 148 quality of the models, we compare the 13 resulting 3D models with the corresponding 149 experimental structure using the root mean square deviation (RMSD). TM-align was 150 151 152 153 154 155

156

\subsection{Molecular docking evaluation}

158 Numerous structures of potassium blockers have been reported. To identify potential 159 drug binding sites on the GiK protein, we selected 290 potassium blockers from the Drug bank (www.drugbank.ca), Sigma profile (www.sigmaaldrich.com) and Zinc (http://zinc.docking.org) (Irwin et al. 2012) databases. Prior to docking, all structures were energy minimized using Maestro 2017-1 (Schrödinger 2017). The docking simulations were carried out using AutoDock Vina software, employing a Lamarckian genetic algorithm (Trott \& Olson 2010), with a grid box of $126 \AA^{3}$ and 9 binding modes. The complexes and poses between 3D-GiK and potassium blockers were analyzed using Maestro 2017-1 (Schrödinger 2017). The results are reported as binding energy of ligand and protein in $\mathrm{kcal} / \mathrm{mol}$. 
169

170

171

172

173

174

175

176

177

178

179

180

181

182

183

184

185

186

187

188

189

190

191

192

193

194

195

196

\section{Results}

\subsection{Identification and characterization of the putative potassium channel GiK}

We performed BLAST searches of the Giardia genome database. We used the whole sequence of fifty-one potassium channels genomic sequences of different species as queries (Supplementary Table 1). The uncharacterized protein GL50803_101194, GiK (GenBank Accession: XP_001709490), showed $24-50 \%$ identity and $50-90 \%$ positivity with 21 different types of voltage-gated potassium channels (Table 1). Physicochemical properties were obtained (Table 2). These properties enabled establishment of GiK molecular weight, stability index, isoelectric point, aliphatic index, and Grand Average of Hydropathicity (GRAVY) of GiK. The instability index indicates that GiK might be unstable in nature (instability index $>40$ ). The aliphatic index, a factor in protein thermal stability, is related to the mole fraction of Ala, Ile, Leu, and Val in the protein. The aliphatic index of GiK 93.28 indicates a thermally stable protein that contains high amount of hydrophobic amino acids (Supplementary Figure 1). The negative value of GRAVY indicates that GiK is a hydrophilic protein (Wilkins et al. 1999). The prediction of disordered regions in GiK suggests that this protein has 11 intrinsically disordered regions that could be involved in important Giardia functions (Supplementary Figure 2). The membrane topology and the analysis of the main features of $\mathrm{K}^{+}$channels show that GiK is a membrane protein that possesses seven helical transmembrane (HTM) regions. Further, evidence shows a highly conserved pore-loop sequence that determines $\mathrm{K}^{+}$channel selectivity (Fig. 1). According to databases of protein signatures, GiK contains: a domain related to ionic channels, Ion_trans_2 domain; domains related to voltage-gated potassium channels, 215625 and 236711; one domain associated with signal transduction, 227696; two fingerprints of potassium channel, 2POREKCHANEL and KCHANNEL; and one fingerprint related with EAG/ELK/ERG channels (EAGCHANLFMLY). These results suggest that this protein is a potassium channel (Fig. 2 and Table 3). 
197 The pore-forming domain is highly conserved in all types of $\mathrm{K}^{+}$channels. An alignment 198 revealed that all sequences that showed homology with GiK present the pore signature 199 sequence S/TXGXGX. GiK has the residues SIASIGYGD, similar to TFLSIGYG, which

200 are present in small conductance calcium-activated potassium channels (SKCa) (Shin 201 et al. 2005) (Fig. 3). Finally, using PredictProtein server (Yachdav et al. 2014), we 202 predicted GiK has potassium channel activity with $36 \%$ reliability.

\section{$203 \quad 3.2$ Modeling and structure quality of GiK protein}

204 The prediction of the 3D-GiK structure was done by homology modeling. The search for 205 a structural template for GiK protein revealed identity with four resolved protein 206 structures. Two structures were the open and closed state of a high conductance 207 calcium-activated potassium channel from Aplysia californica (PDB ID: 5TJ6, open 208 state, and 5TJl, closed state), with $23 \%$ sequence identity. The other two structures 209 were the open and closed state of a potassium channel subfamily $T$ member 1 from 210 Gallus gallus (PDB: 5U70, open state, and 5U76, closed state) with 19\% sequence 211 identity (Supplementary Fig. 3).

212 Model construction was performed using five homology modelling servers: I-TASSER, 213 RaptorX, Phyre2, Swiss model, and Modeller 9.18. Using the four templates, a 214 modelling protocol was constructed for each program. The final dataset includes 215 thirteen 3D-GiK models covering a wide range of quality. The global quality of each 216 theoretical model was validated by the Ramachandran plot analysis, QMEAN score, Z 217 score, ERRATscore, and Verify 3D. Modeller 9.18 program produced the best 3D-GiK 218 model, using the sequence 5TJI as template (Table 4). Figures 4A-C show the resulting 219 ratio of Z-score and the QMEAN score obtained for GiK. The z-score value, -5.07 , is in 220 the range of native conformations. This can be seen clearly when the score is compared 221 to the scores of other experimentally determined protein structures with the same 222 number of residues. Further, the QMEAN4 score is in the range of a good experimental 223 structure (0.296). Additionally, the Ramachandran plot analysis confirms that this model 224 is characterized by stereochemical parameters of a stable structure, with $94.2 \%$ of 225 residues in the most favored region, $4.6 \%$ in the allowed region, and $1.2 \%$ in the 226 disallowed region (Fig. 4). Finally, according to the QMEANBrane tool estimation, the 
227 3D-GiK model is in the range expected for a membrane protein (Fig. 5). Figure 6 shows 228 the monomeric and tetrameric form, and the pore cavity.

229

\subsection{Molecular docking}

231 Molecular docking permits prediction of the most probable position, orientation, and

232 conformation of interactions between a ligand and macromolecule (Ferreira et al. 2015).

233 To predict binding free energy to GiK, 290 potassium blockers were investigated

234 (Supplementary Table 2). The overall docking energy of a given ligand molecule was

235 expressed in $\mathrm{kcal} / \mathrm{mol}$. This approach revealed 110 molecules exhibiting the best

236 binding free energies (-4 to $-11 \mathrm{kcal} / \mathrm{mol}$ ) (Table 5). Of these, 39 are commercially

237 available compounds. Interestingly, these drugs bind in three specific hydrophobic

238 pockets of GiK. We labeled these regions I, II, and III (Fig. 7). As shown in Table 6, 13

239 residues are important for binding in region I, located on the S6 transmembrane region

240 of the channel. Of these, 10 are hydrophobic and three are polar. For region II, nine

241 residues located on the S5-S6 linker and S6 portion of the channel interact with the

242 various docked ligands. Of these, five are hydrophobic and four are polar. For region III,

24312 extracellular residues are important for ligand interaction. Eight are hydrophobic and

244 four are polar. The major residues observed to interact with more of the ligands were

245 Leu65, Gly113, Gln116, Leu117, Tyr120, Met122, Phe125, Ile127 and Arg129, in region

246 II. More negative free binding energy results in the formation of stronger complexes. We

247 analyzed the interaction maps of the three molecules with highest binding free energies

248 that bind to different pockets of the GiK protein. The ligand with the highest score was

249 the $\mathrm{K}^{+}$channel blocker 6,10-diaza-3(1,3)8,(1,4)-dibenzena-1,5(1,4)-diquinolinacy

250 clodecaphane (UCL 1684, $-11.2 \mathrm{kcal} / \mathrm{mol}$ ). This drug was observed to interact with GiK

251 in region I forming hydrophobic interactions with Phe218, Val221, Val222, Leu225,

252 Tyr226, Val247, Leu250 and Leu276. The competitive antagonist of GABA receptors,

253 bicuculline, had the highest score $(-11.2 \mathrm{kcal} / \mathrm{mol})$ for interaction with GiK in region II.

254 This drug forms: hydrophobic interactions with Gly113, Gln116, Leu117, Tyr118,

255 Tyr120, Met122, Ser124, Phe125, Ser126 and Arg129. Further, bicuculline forms $\pi-\pi$

256 interactions with Phe125 and Tyr68. Finally, the bioactive alkaloid, verruculogen,

257 interacts with GiK site III by hydrophobic interactions with Val348, Pro347, Val377, 
258 Met378 and Ile411. Further, verruculogen interacts by polar interaction with Ser346 259 (Table 6, Fig. 8).

260

\section{Discussion}

262 In this report, we provide in silico evidence indicating the protein XP_001709490 from 263 Giardia lamblia (GiK) is a membrane protein, with conserved potassium channels 264 features. GiK presents seven HTM regions and the pore signature sequence 265 SIASIGYGD. This sequence is associated with $\mathrm{K}^{+}$selectivity in small conductance 266 calcium-activated potassium channels. The presence of the lon_trans_2 domain related 267 to voltage-gated potassium channels suggests that GiK could be activated by either 268 electrical means or by increasing calcium concentrations in the cell. Additional studies are necessary to understand the voltage-gated and ion selectivity in GiK.

270 Transmembrane protein GiK presents hydrophobic regions containing a high fraction of 271 non-polar amino acids. It also presents hydrophilic regions containing a high fraction of 272 polar amino acids (Supplementary Figures 1 and 4). The GRAVY value of -0.053 273 indicates that GiK could establish interactions with water; it can be highly hydrated in 274 aqueous media. GiK contains protein regions that do not fold into defined tertiary 275 structure. These are structural disorders commonly labeled intrinsically disordered 276 regions (IDRs). IDRs perform a central role in regulation of signaling pathways and 277 crucial cellular processes. They are frequently associated with disease. For these 278 reasons, there is growing interest in IDRs as potential targets for drug design (Calcada et al. 2015; Cheng et al. 2006). The prediction of 14 flexible disordered regions in GiK

280

281 suggests that this protein may be important in various Giardia functions. This important preliminary evidence indicates that GiK is a promising subject for future study.

282

Potassium channels regulate multiple cellular functions in both electrically excitable and 283 non-excitable cells. Therefore, they are attractive targets for drug design. Current trends in drug discovery focus on target identification and in silico compound design. We 285 sought to determine whether GiK could be a potential drug target in Giardia. First, we 
287 modeling. The search for templates showed only two resolved structures: a high 288 conductance calcium-activated potassium channel from Aplysia californica (PDB ID: 289 5TJ6 and 5TJI) and a potassium channel subfamily T member 1 from Gallus gallus 290 (PDB: 5U70 and 5U76). In this work, GiK presents 23 and 19\% of sequence identity 291 with the templates. Root Mean Square Deviation (RMSD) is a quantitative measure of 292 the similarity between two superimposed atomic coordinates. When using RMSD to 293 compare protein structures, the RMSD distribution depends on the size of the protein 294 and of the homology between the templates, among others (Kufareva \& Abagyan 2012). 295 Using multiple approaches we generated 13 structural models of GiK, the quality 296 analysis of individual models showed that even though, models obtained with Swiss model and Phyre2 had the lower RMSD values, only $50-70 \%$ of residues were modelled. The percentage of residues in the allowed regions was expected to be more than $90 \%$ for a good model. The Modeller program produced acceptable models. The best result was obtained employing the PDB ID: 5TJI (closed state); 500 a.a aligned, results from a Ramachandran plot showed $94.2 \%$ of residues in the most favored 302 region. Even though the structures obtained with 5 U70 and 5TJ6 showed $90 \%$ of residues in the most favored region, the overall quality factor (Bagal et al.) value of 5TJI is the highest (69.24\%) and is within the accepted range. Besides, it is important to 305 emphasize that in addition to RMSD, the generation of Z-score is also a measure of statistical significance between matched structures and reflects the degree of modelling success (Dalton \& Jackson 2007), the Z-score value (-5.07) indicates that the overall geometrical quality of the model generated by Modeller using the template 5TJI was within the acceptable range for big proteins. The overall results from RAMPAGE, QMEAN and Verify 3D indicate the 3D modeled GiK protein is of good quality. After building the 3D structure of $\mathrm{GiK}$, we screened 290 potassium channel blockers. The docking results showed 110 potassium channel blockers with high affinity for the GiK protein. Thirty-nine of these showed similar binding modes in three specific regions, labelled I to III. They interact principally with hydrophobic and aromatic residues such as

315 Phe, Tyr, Leu and Val. In agreement with results described for different potassium blockers, the ring stacking, hydrophobic interactions with several aromatic side chains and polar interactions take place mainly in S5 and S6 (Marzian et al. 2013; Saxena et 
318 al. 2016). The ionic channels can be switched or gated between an open and closed 319 state by external signals such as changes in transmembrane voltage, binding of ligands, 320 and mechanical stress. Some $\mathrm{K}^{+}$channels possess a highly hydrophobic inner pore that 321 can function as an effective barrier to ion permeation (Aryal et al. 2015). Our results 322 suggest that GiK is a calcium potassium activated channel with a hydrophobic inner 323 pore. Additional research is needed to confirm this finding. We plan to expand our 324 studies in this area in the future. (Liu \& Kokubo 2017; Martins et al. 2018).

325 Other authors have reported successful computational screening of $\mathrm{K}^{+}$channels. These 326 reports demonstrate that computational screening is an effective method for rapidly 327 discovering new channels blockers from large databases (Kingsley et al. 2017; Liu et al. 328 2003). Hong Liu and coworkers identified 14 natural compound of relatively lower 329 binding energy. These researchers used a docking virtual screening approach based 330 upon a three-dimensional model of the eukaryotic $\mathrm{K}^{+}$channels. Experimental results 331 showed that four of these exerted potent and selective inhibitory effect on $\mathrm{K}^{+}$channels 332 (Liu et al. 2003). Interestingly, some of the potassium channel blockers in our study 333 have been employed with some success for their antiparasite activity. Verruculogen, 334 clofilium, clotrimazole, trifluoroperazine, bicuculline methiodide, tubocurarin, and 335 dequalinium chloride affect the growth of Trypanosoma bruceii, Leishmania donovani, 336 Plasmodium falciparum and Trichomonas vaginalis (Della Casa et al. 2002; Nam et al. 337 2011; Rateb et al. 2013; Waller et al. 2008). Quinidine inhibits the cell division in 338 Tetrahymena pyriformis (Conklin et al. 1970). Trifluoperazine alters the motility in 339 Paramecium sp. (Otter et al. 1984). Disodium cromoglycate and terfenadine show 340 activity in infection models of Toxoplasma gondii and Plasmodium yoelli nigeriensis 341 (Rezaei et al. 2016; Singh \& Puri 1998). In Giardia lamblia, trifluoroperazine, a 342 calmodulin antagonist, inhibits excystment (Bernal et al. 1998). It remains uncertain 343 whether potassium channels are the targets of these compounds.

\section{5. Conclusion}

345 Using structural bioinformatics, we identified the hypothetical protein XP_001709490 346 from Giardia lamblia as a potassium channel, GiK. By protein docking analysis, we 347 found 39 commercial potassium channel blockers that have affinity for this protein. 
348 These blockers are predicted to bind in three specific regions on the protein. The

349 novelty of this work lies in the use of the model 3D-GiK structure to screen compounds

350 with theoretical affinity. Some of the drugs predicted by the model to be effective have

351 demonstrated antiparasitic activity in in vitro and in vivo assays. Experimental analyses

352 are needed to confirm the activity of these drugs on Giardia. The low homology of GiK

353 with proteins in the human genome contributes to its potential as a target of specific

354 pharmacological agents.

\section{References}

357

358

359

360

361

362

363

364

365

366

367

368

369

370

371

372

373

374

375

376

377

378

379

380

381

382

383

384

385

386

387
Ansell BR, McConville MJ, Ma'ayeh SY, Dagley MJ, Gasser RB, Svard SG, and Jex AR. 2015. Drug resistance in Giardia duodenalis. Biotechnol Adv 33:888-901. 10.1016/j.biotechadv.2015.04.009

Arnold K, Bordoli L, Kopp J, and Schwede T. 2006. The SWISS-MODEL workspace: a web-based environment for protein structure homology modelling. Bioinformatics 22:195-201. 10.1093/bioinformatics/bti770

Aryal P, Sansom MS, and Tucker SJ. 2015. Hydrophobic gating in ion channels. J Mol Biol 427:121-130. 10.1016/j.jmb.2014.07.030

Bagal SK, Brown AD, Cox PJ, Omoto K, Owen RM, Pryde DC, Sidders B, Skerratt SE, Stevens EB, Storer RI, and Swain NA. 2013. Ion channels as therapeutic targets: a drug discovery perspective. J Med Chem 56:593-624. 10.1021/jm3011433

Benkert P, Tosatto SCE, and Schomburg D. 2008. QMEAN: A comprehensive scoring function for model quality assessment. Proteins: Structure, Function, and Bioinformatics 71:261-277. 10.1002/prot.21715

Berman H, Henrick K, Nakamura H, and Markley JL. 2007. The worldwide Protein Data Bank (wwPDB): ensuring a single, uniform archive of PDB data. Nucleic Acids Res 35:D301-303. 10.1093/nar/gkl971

Bernal RM, Tovar R, Santos JI, and Munoz ML. 1998. Possible role of calmodulin in excystation of Giardia lamblia. Parasitol Res 84:687-693.

Bhattacharya D, and Cheng J. 2013. 3Drefine: Consistent protein structure refinement by optimizing hydrogen bonding network and atomic-level energy minimization. Proteins: Structure, Function, and Bioinformatics 81:119-131. 10.1002/prot.24167

Bhattacharya D, Nowotny J, Cao R, and Cheng J. 2016. 3Drefine: an interactive web server for efficient protein structure refinement. Nucleic Acids Research 44:W406W409. 10.1093/nar/gkw336

Biagini GA, Lloyd D, Kirk K, and Edwards MR. 2000. The membrane potential of Giardia intestinalis. FEMS Microbiol Lett 192:153-157.

Biasini M, Bienert S, Waterhouse A, Arnold K, Studer G, Schmidt T, Kiefer F, Cassarino TG, Bertoni M, Bordoli L, and Schwede T. 2014. SWISS-MODEL: modelling protein tertiary and quaternary structure using evolutionary information. Nucleic Acids Research 42:W252-W258. 10.1093/nar/gku340 
388 Bordoli L, Kiefer F, Arnold K, Benkert P, Battey J, and Schwede T. 2008. Protein structure

389

390

391

392

393

394

395

396

397

398

399

400

401

402

403

404

405

406

407

408

409

410

411

412

413

414

415

416

417

418

419

420

421

422

423

424

425

426

427

428

429

430

431 homology modeling using SWISS-MODEL workspace. Nat Protocols 4:1-13.

Bowie J, Luthy R, and Eisenberg D. 1991. A method to identify protein sequences that fold into a known three-dimensional structure. Science 253:164-170. 10.1126/science. 1853201

Calcada EO, Korsak M, and Kozyreva T. 2015. Recombinant Intrinsically Disordered Proteins for NMR: Tips and Tricks. Adv Exp Med Biol 870:187-213. 10.1007/9783-319-20164-1 6

Carter ER, Nabarro LE, Hedley L, and Chiodini PL. 2018. Nitroimidazole-refractory giardiasis: a growing problem requiring rational solutions. Clin Microbiol Infect 24:37-42. 10.1016/j.cmi.2017.05.028

Colovos C, and Yeates TO. 1993. Verification of protein structures: patterns of nonbonded atomic interactions. Protein Science : A Publication of the Protein Society 2:1511-1519.

Conklin KA, Heu P, and Chou SC. 1970. Quinine--effect on Tetrahymena pyriformis. II. Comparative activity of the stereoisomers, quinidine and quinine. $J$ Pharm Sci 59:704-705.

Corpet F. 1988. Multiple sequence alignment with hierarchical clustering. Nucleic Acids Res 16:10881-10890.

Chen YP, and Chen F. 2008. Identifying targets for drug discovery using bioinformatics. Expert Opin Ther Targets 12:383-389. 10.1517/14728222.12.4.383

Cheng Y, LeGall T, Oldfield CJ, Mueller JP, Van YY, Romero P, Cortese MS, Uversky $\mathrm{VN}$, and Dunker AK. 2006. Rational drug design via intrinsically disordered protein. Trends Biotechnol 24:435-442. 10.1016/j.tibtech.2006.07.005

Chinea G, Padron G, Hooft RWW, Sander C, and Vriend G. 1995. The use of positionspecific rotamers in model building by homology. Proteins: Structure, Function, and Bioinformatics 23:415-421. 10.1002/prot.340230315

Dalton JA, and Jackson RM. 2007. An evaluation of automated homology modelling methods at low target template sequence similarity. Bioinformatics 23:1901-1908. 10.1093/bioinformatics/btm262

Della Casa V, Noll H, Gonser S, Grob P, Graf F, and Pohlig G. 2002. Antimicrobial activity of dequalinium chloride against leading germs of vaginal infections. Arzneimittelforschung 52:699-705. 10.1055/s-0031-1299954

Ellekvist P, Ricke CH, Litman T, Salanti A, Colding H, Zeuthen T, and Klaerke DA. 2004. Molecular cloning of a $\mathrm{K}(+)$ channel from the malaria parasite Plasmodium falciparum. Biochem Biophys Res Commun 318:477-484. 10.1016/j.bbrc.2004.04.049

Escobedo AA, and Cimerman S. 2007. Giardiasis: a pharmacotherapy review. Expert Opin Pharmacother 8:1885-1902. 10.1517/14656566.8.12.1885

Ferreira LG, Dos Santos RN, Oliva G, and Andricopulo AD. 2015. Molecular docking and structure-based drug design strategies. Molecules 20:13384-13421. 10.3390/molecules200713384

Fiser A, Do RK, and Sali A. 2000. Modeling of loops in protein structures. Protein Science : A Publication of the Protein Society 9:1753-1773. 
432 Grunnet M, MacAulay N, Jorgensen NK, Jensen B, Olesen S-P, and Klaerke DA. 2002.

433 Regulation of cloned, Ca2+-activated $\mathrm{K}+$ channels by cell volume changes.

434

435

436

437

438

439

440

441

442

443

444

445

446

447

448

449

450

451

452

453

454

455

456

457

458

459

460

461

462

463

464

465

466

467

468

469

470

471

472

473

474

475

476

477

Henikoff S, and Henikoff JG. 1994. Protein family classification based on searching a database of blocks. Genomics 19:97-107. 10.1006/geno.1994.1018

Irwin JJ, Sterling T, Mysinger MM, Bolstad ES, and Coleman RG. 2012. ZINC: a free tool to discover chemistry for biology. J Chem Inf Model 52:1757-1768. $10.1021 / \mathrm{ci} 3001277$

Jimenez V, and Docampo R. 2012. Molecular and electrophysiological characterization of a novel cation channel of Trypanosoma cruzi. PLoS Pathog 8:e1002750. 10.1371/journal.ppat.1002750

Jones $\mathrm{P}$, Binns $\mathrm{D}$, Chang HY, Fraser M, Li W, McAnulla C, McWilliam H, Maslen J, Mitchell A, Nuka G, Pesseat S, Quinn AF, Sangrador-Vegas A, Scheremetjew M, Yong SY, Lopez R, and Hunter S. 2014. InterProScan 5: genome-scale protein function classification. Bioinformatics 30:1236-1240. 10.1093/bioinformatics/btu031

Kelley LA, Mezulis S, Yates CM, Wass MN, and Sternberg MJE. 2015. The Phyre2 web portal for protein modeling, prediction and analysis. Nat Protocols 10:845-858. 10.1038/nprot.2015.053

Kingsley B, Kumari S, Appian S, and Brindha P. 2017. In silico Docking Studies on ATPSensitive K+Channel, Insulin Receptor and Phosphorylase kinase Activity by Isolated Active Principles of Stereospermum tetragonum DC.

Kufareva I, and Abagyan R. 2012. Methods of protein structure comparison. Methods $\mathrm{Mol}$ Biol 857:231-257. 10.1007/978-1-61779-588-6_10

Leitsch D. 2015. Drug Resistance in the Microaerophilic Parasite Giardia lamblia. Curr Trop Med Rep 2:128-135. 10.1007/s40475-015-0051-1

Liu H, Li Y, Song M, Tan X, Cheng F, Zheng S, Shen J, Luo X, Ji R, Yue J, Hu G, Jiang $\mathrm{H}$, and Chen K. 2003. Structure-based discovery of potassium channel blockers from natural products: virtual screening and electrophysiological assay testing. Chem Biol 10:1103-1113.

Liu K, and Kokubo H. 2017. Exploring the Stability of Ligand Binding Modes to Proteins by Molecular Dynamics Simulations: A Cross-docking Study. J Chem Inf Model 57:2514-2522. 10.1021/acs.jcim.7b00412

Lovell SC, Davis IW, Arendall WB, de Bakker PIW, Word JM, Prisant MG, Richardson JS, and Richardson DC. 2003. Structure validation by C $\alpha$ geometry: $\phi, \psi$ and C $\beta$ deviation. Proteins: Structure, Function, and Bioinformatics 50:437-450. 10.1002/prot. 10286

Luthy R, Bowie JU, and Eisenberg D. 1992. Assessment of protein models with threedimensional profiles. Nature 356:83-85.

Ma J, Peng J, Wang S, and Xu J. 2012. A conditional neural fields model for protein threading. Bioinformatics 28:i59-i66. 10.1093/bioinformatics/bts213

Ma J, Wang S, Zhao F, and Xu J. 2013. Protein threading using context-specific alignment potential. Bioinformatics 29:i257-i265. 10.1093/bioinformatics/btt210

Marchler-Bauer A, Bo Y, Han L, He J, Lanczycki CJ, Lu S, Chitsaz F, Derbyshire MK, Geer RC, Gonzales NR, Gwadz M, Hurwitz DI, Lu F, Marchler GH, Song JS, Thanki N, Wang Z, Yamashita RA, Zhang D, Zheng C, Geer LY, and Bryant SH. 
478

479

480

481

482

483

484

485

486

487

488

489

490

491

492

493

494

495

496

497

498

499

500

501

502

503

504

505

506

507

508

509

510

511

512

513

514

515

516

517

518

519

520

521

522

523

2017. CDD/SPARCLE: functional classification of proteins via subfamily domain architectures. Nucleic Acids Res 45:D200-D203. 10.1093/nar/gkw1129

Maroulis SL, Schofield PJ, and Edwards MR. 2000. The role of potassium in the response of Giardia intestinalis to hypo-osmotic stress. Mol Biochem Parasitol 108:141-145.

Martí-Renom MA, Stuart AC, Fiser A, Sánchez R, and FM, and Šali A. 2000. Comparative Protein Structure Modeling of Genes and Genomes. Annual Review of Biophysics and Biomolecular Structure 29:291-325. 10.1146/annurev.biophys.29.1.291

Martins LC, Torres PHM, de Oliveira RB, Pascutti PG, Cino EA, and Ferreira RS. 2018. Investigation of the binding mode of a novel cruzain inhibitor by docking, molecular dynamics, ab initio and MM/PBSA calculations. J Comput Aided Mol Des 32:591605. 10.1007/s10822-018-0112-3

Marzian S, Stansfeld PJ, Rapedius M, Rinne S, Nematian-Ardestani E, Abbruzzese JL, Steinmeyer K, Sansom MS, Sanguinetti MC, Baukrowitz T, and Decher N. 2013. Side pockets provide the basis for a new mechanism of Kv channel-specific inhibition. Nat Chem Biol 9:507-513. 10.1038/nchembio.1271

Nam TG, McNamara CW, Bopp S, Dharia NV, Meister S, Bonamy GM, Plouffe DM, Kato N, McCormack S, Bursulaya B, Ke H, Vaidya AB, Schultz PG, and Winzeler EA. 2011. A chemical genomic analysis of decoquinate, a Plasmodium falciparum cytochrome b inhibitor. ACS Chem Biol 6:1214-1222. 10.1021/cb200105d

Obradovic Z, Peng K, Vucetic S, Radivojac P, Brown CJ, and Dunker AK. 2003. Predicting intrinsic disorder from amino acid sequence. Proteins 53 Suppl 6:566-572. 10.1002/prot. 10532

Otter T, Satir BH, and Satir P. 1984. Trifluoperazine-induced changes in swimming behavior of paramecium: evidence for two sites of drug action. Cell Motil 4:249267.

Pchelintseva E, and Djamgoz MBA. 2018. Mesenchymal stem cell differentiation: Control by calcium-activated potassium channels. J Cell Physiol 233:3755-3768. $10.1002 / j c p .26120$

Peng J, and Xu J. 2010. Low-homology protein threading. Bioinformatics 26:i294-300. 10.1093/bioinformatics/btq192

Pettersen EF, Goddard TD, Huang CC, Couch GS, Greenblatt DM, Meng EC, and Ferrin TE. 2004. UCSF Chimera--a visualization system for exploratory research and analysis. J Comput Chem 25:1605-1612. 10.1002/jcc.20084

Ponce A, Jimenez-Cardoso E, and Eligio-Garcia L. 2013. Voltage-dependent potassium currents expressed in Xenopus laevis oocytes after injection of mRNA isolated from trophozoites of Giardia lamblia (strain Portland-1). Physiol Rep 1:e00186. $10.1002 /$ phy2.186

Prole DL, and Marrion NV. 2012. Identification of putative potassium channel homologues in pathogenic protozoa. PloS one 7:e32264.

Rateb ME, Hallyburton I, Houssen WE, Bull AT, Goodfellow M, Santhanam R, Jaspars M, and Ebel R. 2013. Induction of diverse secondary metabolites in Aspergillus fumigatus by microbial co-culture. RSC Advances 3:14444. 10.1039/c3ra42378f

Rezaei F, Ebrahimzadeh MA, Daryani A, Sharif M, Ahmadpour E, and Sarvi S. 2016. The inhibitory effect of cromolyn sodium and ketotifen on Toxoplasma gondii entrance into host cells in vitro and in vivo. J Parasit Dis 40:1001-1005. 10.1007/s12639014-0623-3 
524 Roy A, Kucukural A, and Zhang Y. 2010. I-TASSER: a unified platform for automated

525

526

527

528

529

530

531

532

533

534

535

536

537

538

539

540

541

542

543

544

545

546

547

548

549

550

551

552

553

554

555

556

557

558

559

560

561

562

563

564

565

566

567 protein structure and function prediction. Nature protocols 5:725-738. 10.1038/nprot.2010.5

Šali A, and Blundell TL. 1993. Comparative Protein Modelling by Satisfaction of Spatial Restraints. J Mol Biol 234:779-815. http://dx.doi.org/10.1006/jmbi.1993.1626

Saxena P, Zangerl-PlessI EM, Linder T, Windisch A, Hohaus A, Timin E, Hering S, and Stary-Weinzinger A. 2016. New potential binding determinant for hERG channel inhibitors. Sci Rep 6:24182. 10.1038/srep24182

Schmidt RS, Macedo JP, Steinmann ME, Salgado AG, Butikofer P, Sigel E, Rentsch D, and Maser P. 2018. Transporters of Trypanosoma brucei-phylogeny, physiology, pharmacology. FEBS J 285:1012-1023. 10.1111/febs.14302

Schrödinger L. 2017. Schrödinger Release 2017-1:. Maestro. New York, NY.

Schwab A, Hanley P, Fabian A, and Stock C. 2008. Potassium channels keep mobile cells on the go. Physiology (Bethesda) 23:212-220. 10.1152/physiol.00003.2008

Shin N, Soh H, Chang S, Kim DH, and Park CS. 2005. Sodium permeability of a cloned small-conductance calcium-activated potassium channel. Biophys J 89:31113119. 10.1529/biophysj. 105.069542

Sigrist CJ, de Castro E, Cerutti L, Cuche BA, Hulo N, Bridge A, Bougueleret L, and Xenarios I. 2013. New and continuing developments at PROSITE. Nucleic Acids Res 41:D344-347. 10.1093/nar/gks1067

Singh N, and Puri SK. 1998. Causal prophylactic activity of antihistaminic agents against Plasmodium yoelii nigeriensis infection in Swiss mice. Acta Trop 69:255-260.

Steinmann ME, Gonzalez-Salgado A, Butikofer P, Maser P, and Sigel E. 2015. A heteromeric potassium channel involved in the modulation of the plasma membrane potential is essential for the survival of African trypanosomes. FASEB $J$ 29:3228-3237. 10.1096/fj.15-271353

Studer G, Biasini M, and Schwede T. 2014. Assessing the local structural quality of transmembrane protein models using statistical potentials (QMEANBrane). Bioinformatics 30:i505-i511. 10.1093/bioinformatics/btu457

Subramanyam P, and Colecraft HM. 2015. Ion channel engineering: perspectives and strategies. J Mol Biol 427:190-204. 10.1016/j.jmb.2014.09.001

Tejman-Yarden N, and Eckmann L. 2011. New approaches to the treatment of giardiasis. Curr Opin Infect Dis 24:451-456. 10.1097/QCO.0b013e32834ad401

Trott O, and Olson AJ. 2010. AutoDock Vina: improving the speed and accuracy of docking with a new scoring function, efficient optimization, and multithreading. $J$ Comput Chem 31:455-461. 10.1002/jcc.21334

Tusnady GE, and Simon I. 1998. Principles governing amino acid composition of integral membrane proteins: application to topology prediction. $J$ Mol Biol 283:489-506. 10.1006/jmbi.1998.2107

Tusnady GE, and Simon I. 2001. The HMMTOP transmembrane topology prediction server. Bioinformatics 17:849-850.

Urrego D, Tomczak AP, Zahed F, Stuhmer W, and Pardo LA. 2014. Potassium channels in cell cycle and cell proliferation. Philos Trans $R$ Soc Lond B Biol Sci 369:20130094. 10.1098/rstb.2013.0094 
568 Waller KL, McBride SM, Kim K, and McDonald TV. 2008. Characterization of two putative potassium channels in Plasmodium falciparum. Malar J 7:19. 10.1186/1475-28757-19

571

572

Watkins RR, and Eckmann L. 2014. Treatment of giardiasis: current status and future directions. Curr Infect Dis Rep 16:396. 10.1007/s11908-014-0396-y

Webb B, and Sali A. 2002. Comparative Protein Structure Modeling Using MODELLER. Current Protocols in Bioinformatics: John Wiley \& Sons, Inc.

Wiederstein M, and Sippl MJ. 2007. ProSA-web: interactive web service for the recognition of errors in three-dimensional structures of proteins. Nucleic Acids Research 35:W407-W410. 10.1093/nar/gkm290

Wilkins MR, Gasteiger E, Bairoch A, Sanchez JC, Williams KL, Appel RD, and Hochstrasser DF. 1999. Protein identification and analysis tools in the ExPASy server. Methods Mol Biol 112:531-552.

Wulff $\mathrm{H}$, Castle NA, and Pardo LA. 2009. Voltage-gated potassium channels as therapeutic targets. Nat Rev Drug Discov 8:982-1001. 10.1038/nrd2983

Yachdav G, Kloppmann E, Kajan L, Hecht M, Goldberg T, Hamp T, Honigschmid P, Schafferhans A, Roos M, Bernhofer M, Richter L, Ashkenazy H, Punta M, Schlessinger A, Bromberg Y, Schneider R, Vriend G, Sander C, Ben-Tal N, and Rost B. 2014. PredictProtein--an open resource for online prediction of protein structural and functional features. Nucleic Acids Res 42:W337-343. 10.1093/nar/gku366

Yang J, Yan R, Roy A, Xu D, Poisson J, and Zhang Y. 2015. The I-TASSER Suite: protein structure and function prediction. Nature methods 12:7-8. 10.1038/nmeth.3213

Zhang Y. 2008. I-TASSER server for protein 3D structure prediction. BMC Bioinformatics 9:40-40. 10.1186/1471-2105-9-40

593

594 


\section{Figure 1 (on next page)}

Transmembrane structure of GiK.

It contains seven transmembrane segments (S1-S7), the P-loops between S5 and S6 form the pore domain. The selectivity filter is in gray. 
89
8080

\begin{tabular}{|c|c|c|c|c|c|c|}
\hline $31 A B C$ & S๑ S2 & S3 (1) & (4) S4 & S50 & ๔ S6 & S78 \\
\hline (1) (O) & (1)D网O & (1)PAO & (ब⿶凵S & OSOD & (1)(1) & (ब) \\
\hline 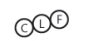 & 미미 & SODOO & (A) & G) $P$ (P) & (C) & $\triangle D^{\oplus}$ \\
\hline (1) 0 & ODODO & (SAOOO & $\triangle \mathbb{A}_{B} \rightarrow$ & (1) $O P D$ & $\triangle(1) A$ & (1) \\
\hline OOODD & ODOD & $\triangle(1) B D$ & $\triangle(1) D$ & ๑๐O९ & (B) & BDOOD \\
\hline OPC & 1000 & (1) M⿵冂卄 & 50 & (1)AOD & $\mathbb{1 0} \infty$ & (DOD \\
\hline POSAD & $(A)(10)$ & (1) & $\triangle \infty$ & ACODOC & $(1) 0$ & $\operatorname{Or} \theta 0$ \\
\hline
\end{tabular}

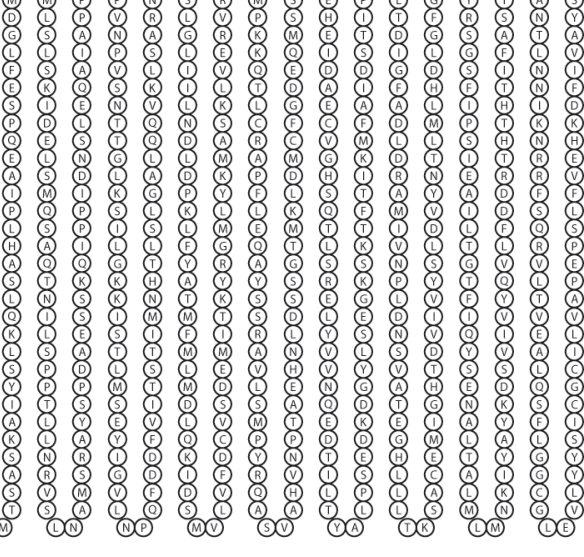

$\mathrm{N}$

(1)

(8) 8

8ோோவ

遏 19 8 .

.

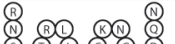

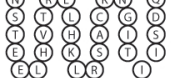

(8)

8 


\section{Figure 2 (on next page)}

Domains and motifs related to potassium channels.

GiK presents domains related to different subtypes of potassium channels. A. Schematic representation. B. Accession number and description of the sequences. 


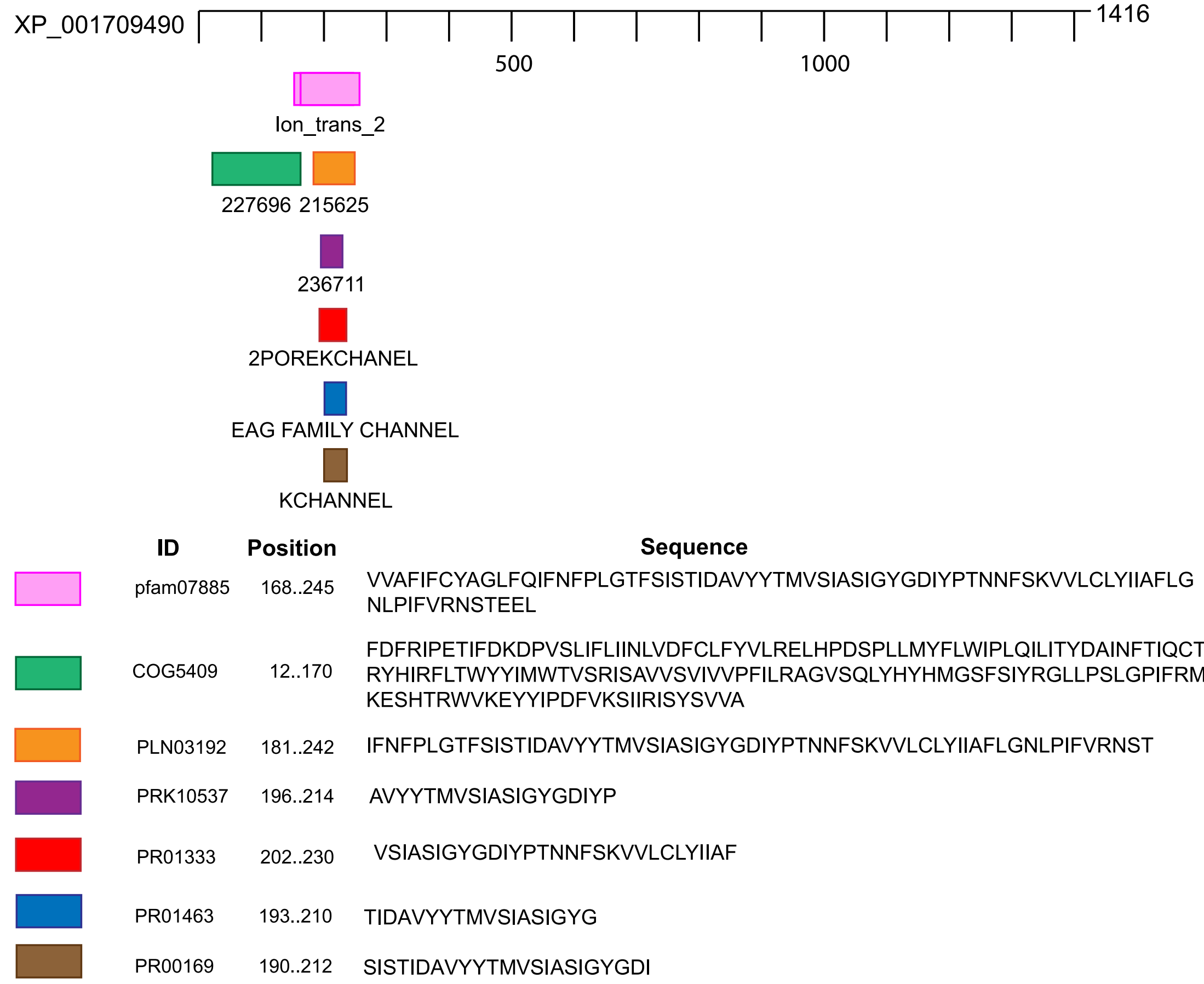




\section{Figure 3}

Multiple sequence alignment of GiK with voltage-gated potassium channels.

The signature sequence T/SXGXGX of the selectivity filter is present in all classes of potassium channels (black square). 


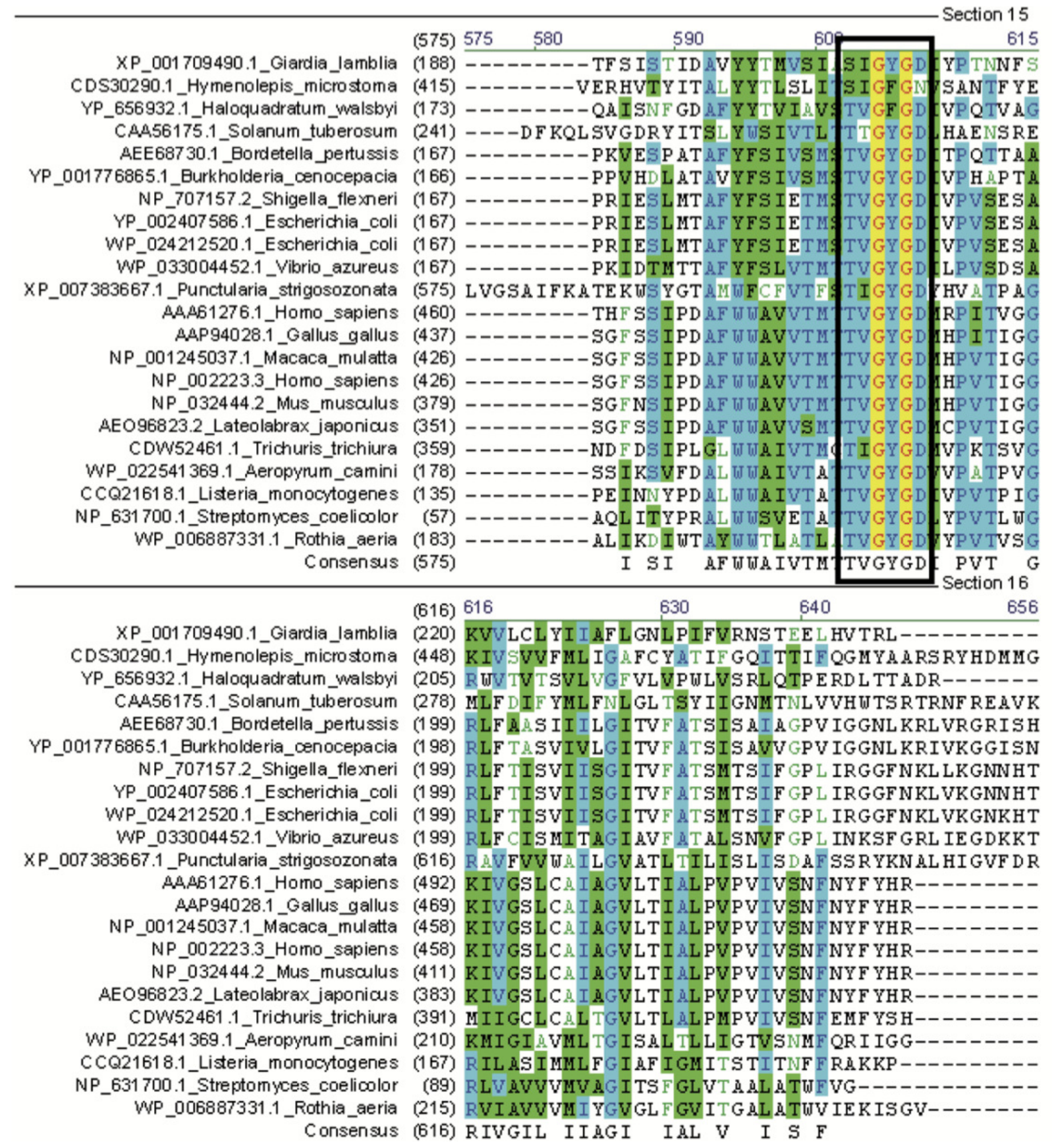




\section{Figure 4}

Structural validation.

A. Normalized QMEAN score of theoretical 3D structure for GiK protein model created with SWISS-MODEL server. B. Graphical representation of the Z-Score of the individual component of QMEAN. C. ProSA-web Z-scores of all proteins chains in PDB determined by X-ray crystallography (light blue) or NMR spectroscopy (dark blue). The Z score of GiK is highlighted as a black dot. D. Ramachandran plot analysis, $94.2 \%$ of total residues are in the most favored region. 

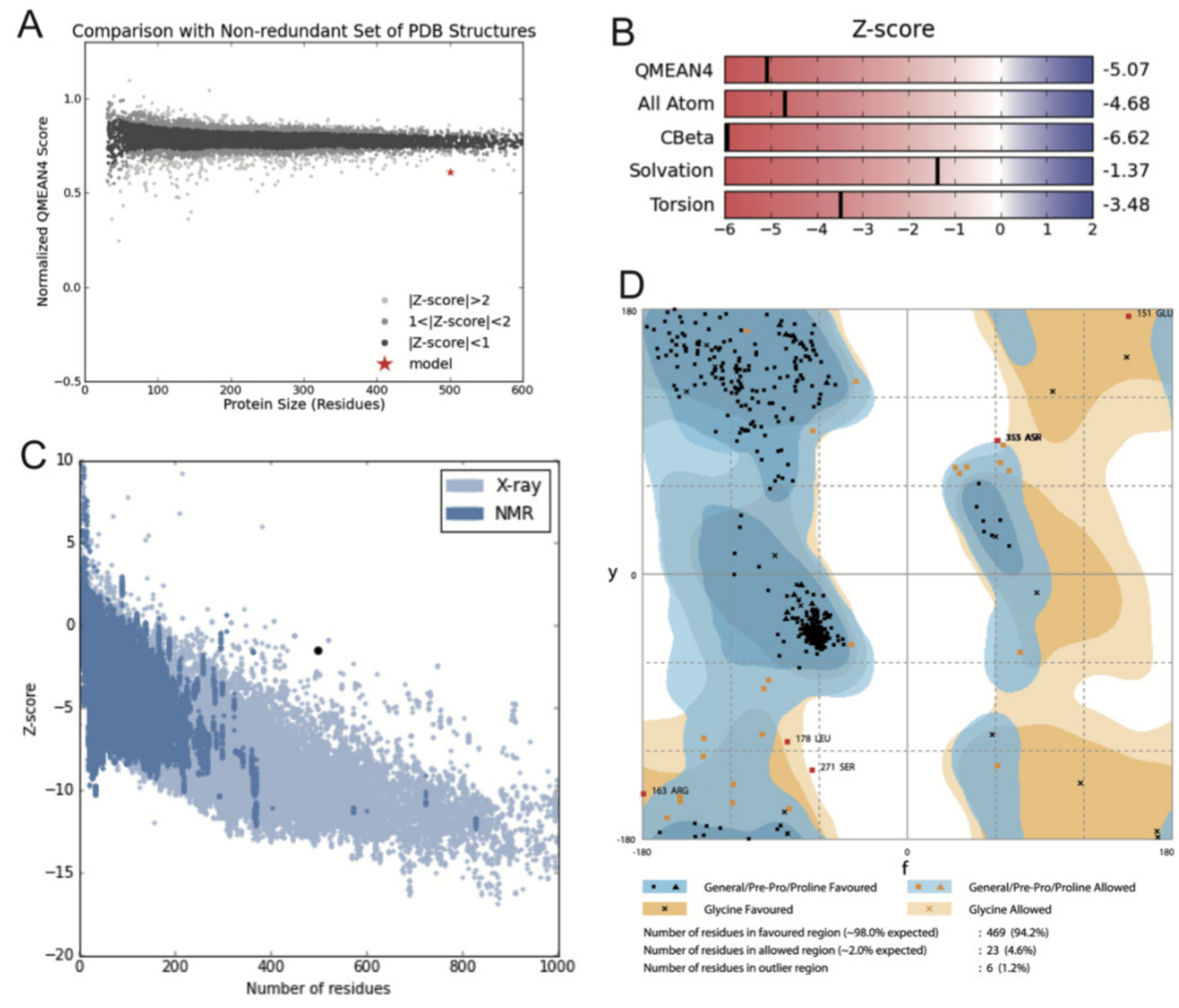
Figure 5

Quality estimation of GiK as a membrane protein.

Prediction done with SWISS-MODEL-QMEANBrane tool. 


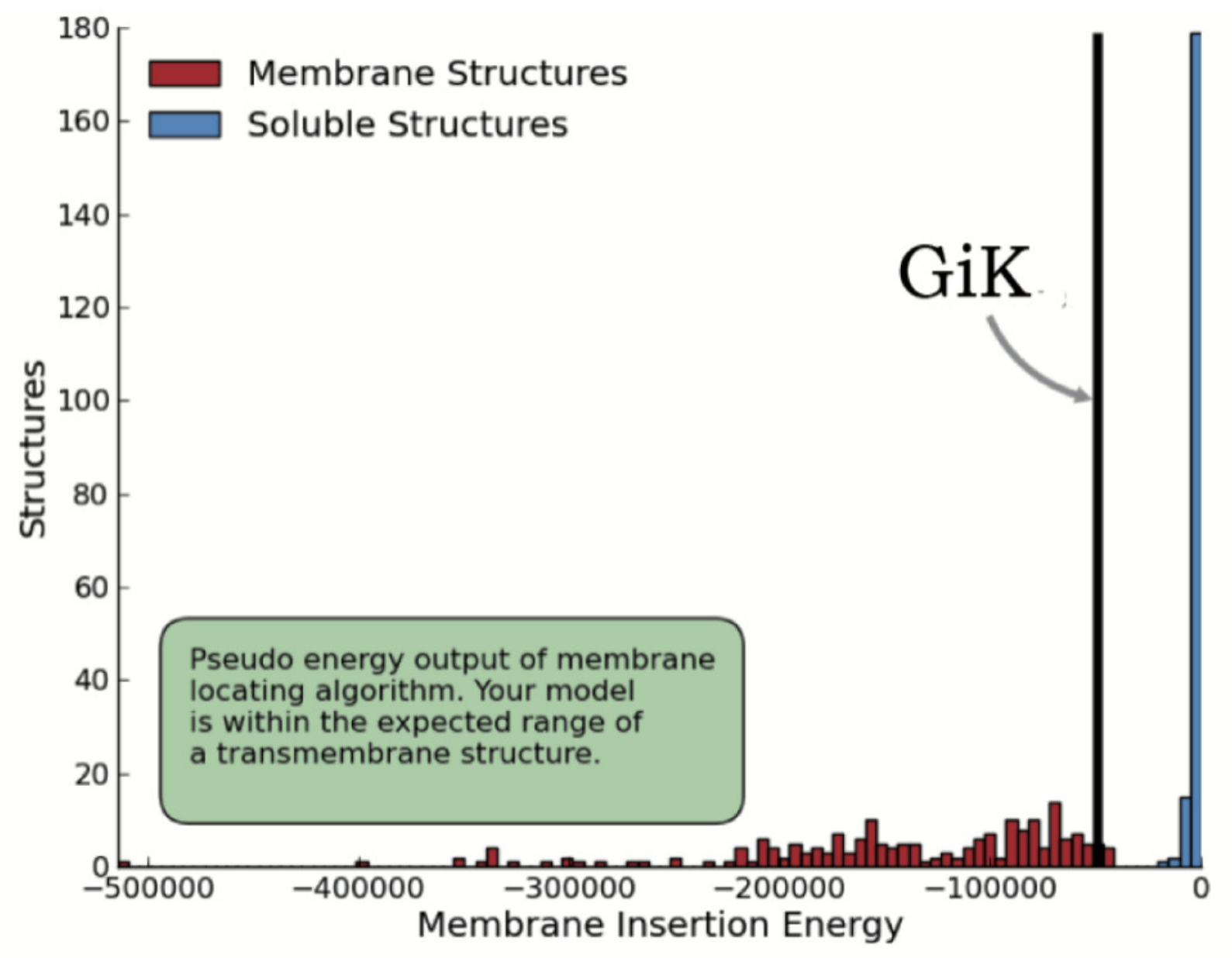


Figure 6

Representation of the 3D-GiK modelled structure.

A. Monomer, B-C. Tetramer. The images were generated using MAESTRO-I software.

A

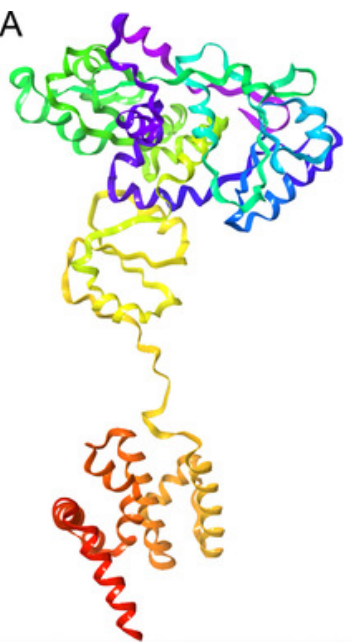

B

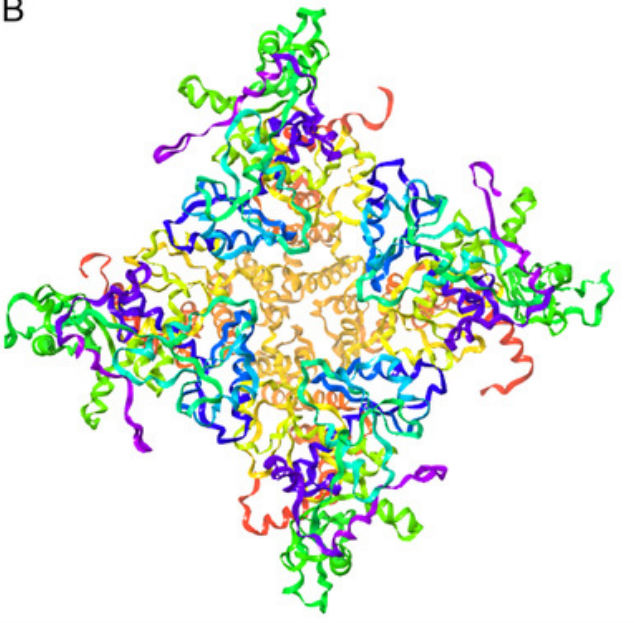

C

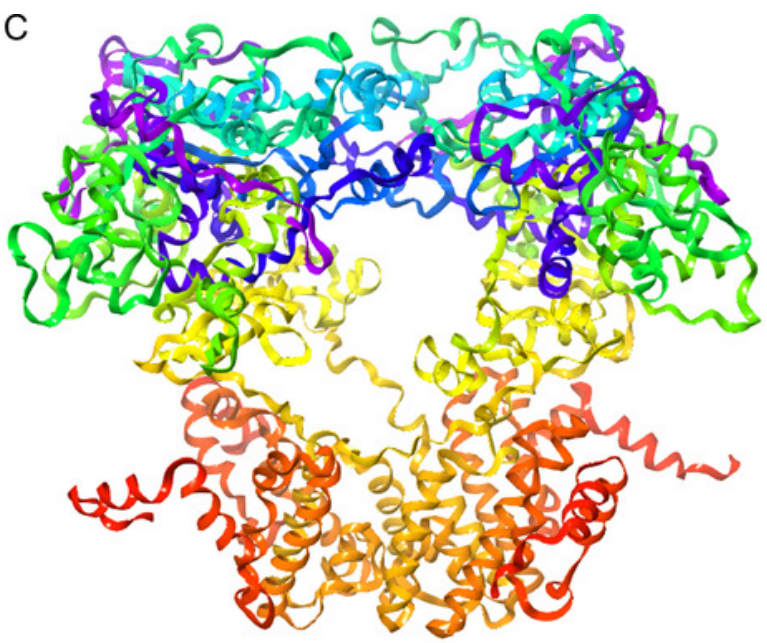


Figure 7

GiK - potassium channel blockers docking simulations (A).

B-D. Magnified views of the boxed regions depict the three potassium blockers channels binding sites (blue region I, red region II and green region III).

A

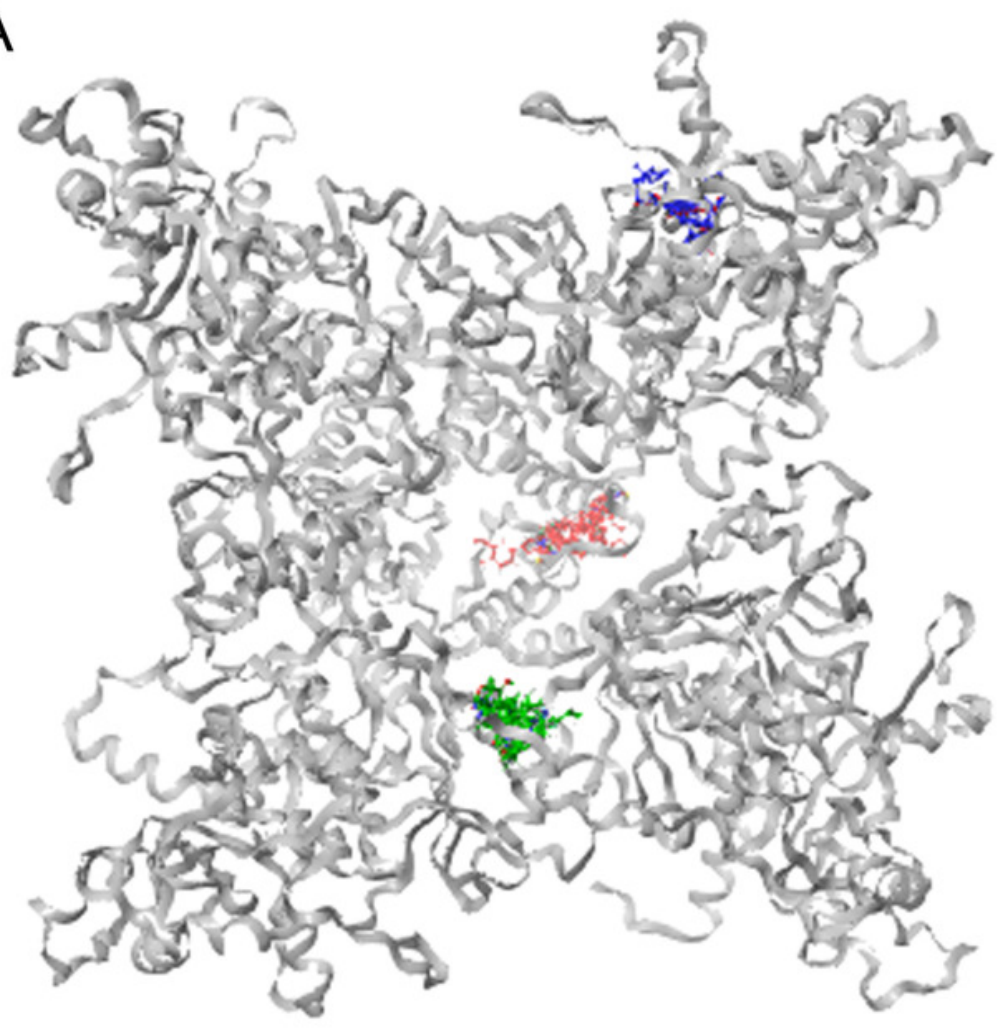

B

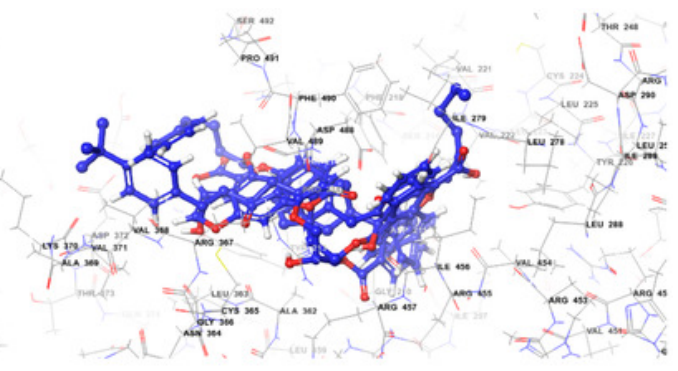

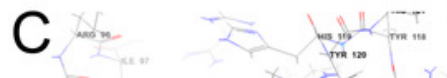

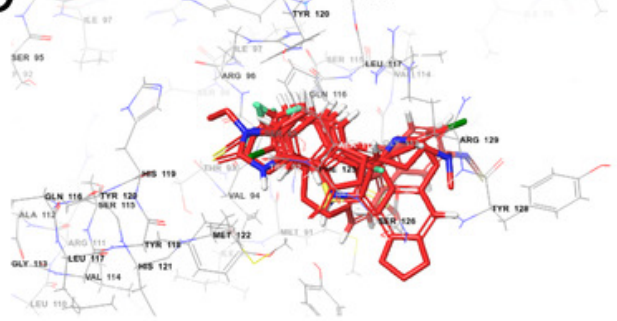

$D^{\text {at } 348}$

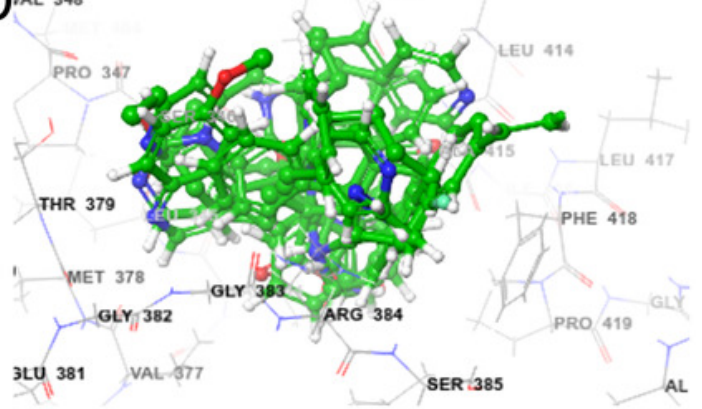


Figure 8

Ligand interaction diagrams.

UCL 1684 (A), Bicuculline (B) or verruculogen (C). Hydrophobic interactions are depicted by green curves, pi-pi interactions are in green-dashed lines, and the polar interactions by curve blue lines.

A

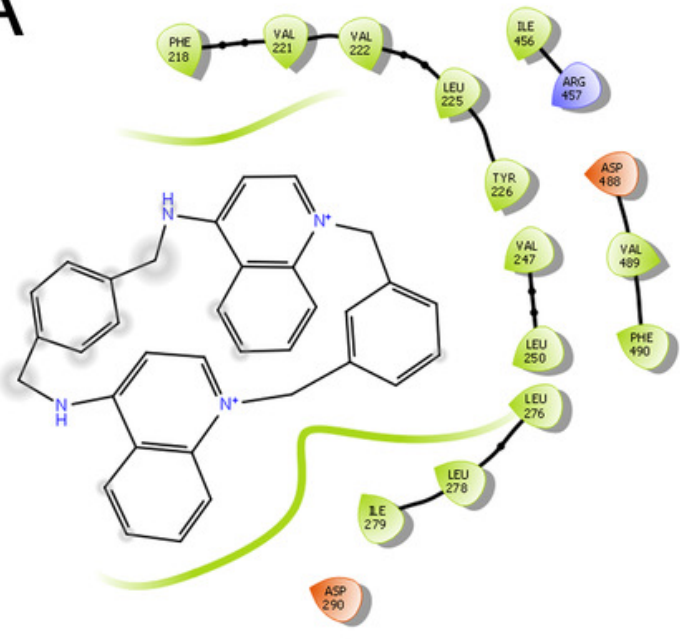

Gharged (negative)
Garged (positive)
Gydine
Hydrophobic
Metal

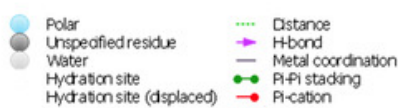

- Saltbridge
Solvert exposure

Hydration site
Hydration site (dsplaced) $\because$ Pifi stading

\section{C}

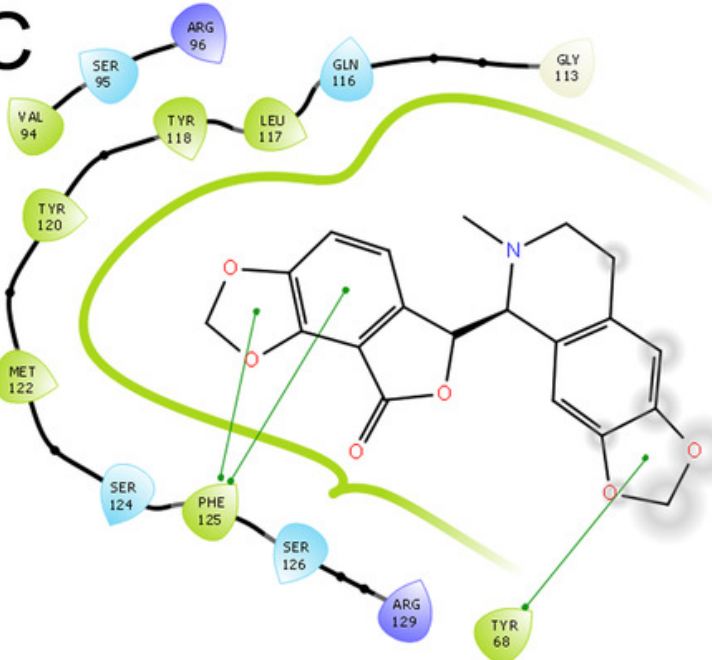

8 Charged (negative)

Glycine

Metal

Polar
Unspedfied residue
Water
Hydration site
Hydration site (dlsplaced)

Salt tridge
Solvent exposure
B

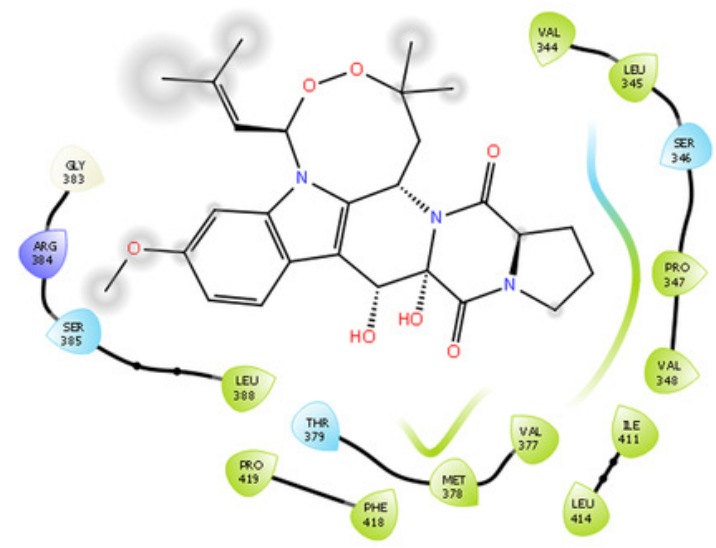

8 charged (negative)
charged (positive)
Gyche

Hydrophobic

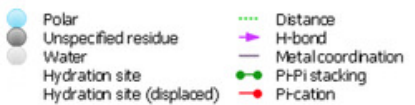

$\begin{array}{ll}- & \text { Sat bridge } \\ \text { Solvent exposure }\end{array}$ 


\section{Table 1 (on next page)}

Sequences producing significant alignments with GiK by BLAST. 


\begin{tabular}{|c|c|c|c|c|c|c|}
\hline $\begin{array}{l}\text { Accession } \\
\text { number }\end{array}$ & Organism & $\begin{array}{l}\text { Type of } \\
\text { channel }\end{array}$ & Score & $\begin{array}{l}\text { E. } \\
\text { value }\end{array}$ & Identities & Positives \\
\hline WP_022541369.1 & Aeropyrum camini & $\mathrm{Kv}$ & 32 & 0.33 & $\begin{array}{l}15 / 49 \\
(31 \%)\end{array}$ & $\begin{array}{l}29 / 49 \\
(59 \%)\end{array}$ \\
\hline AEE68730.1 & Bordetella pertussis & $\mathrm{Kv}$ & 32 & 0.51 & $\begin{array}{l}15 / 43 \\
(35 \%)\end{array}$ & $\begin{array}{l}25 / 43 \\
(58 \%)\end{array}$ \\
\hline YP_001776865.1 & Burkholderia cenocepacia & $\mathrm{Kv}$ & 33 & 0.20 & $\begin{array}{l}16 / 39 \\
(41 \%)\end{array}$ & $\begin{array}{l}25 / 39 \\
(64 \%)\end{array}$ \\
\hline YP_002407586.1 & Escherichia coli & $\mathrm{Kv}$ & 28.9 & 8.6 & $\begin{array}{l}18 / 66 \\
(27 \%)\end{array}$ & $\begin{array}{l}36 / 66 \\
(55 \%)\end{array}$ \\
\hline WP_024212520.1 & Escherichia spp & $\begin{array}{l}\text { Multispecies } \\
\text { Kv }\end{array}$ & 28.9 & 9.8 & $\begin{array}{l}18 / 66 \\
(27 \%)\end{array}$ & $\begin{array}{l}36 / 66 \\
(55 \%)\end{array}$ \\
\hline AAP94028.1 & Gallus gallus & Kv1.3 & 34.7 & 0.27 & $\begin{array}{l}20 / 58 \\
(34 \%)\end{array}$ & $\begin{array}{l}32 / 58 \\
(55 \%)\end{array}$ \\
\hline YP_656932.1 & Haloquadratum walsby & $\mathrm{Kv}$ & 33 & 0.18 & $\begin{array}{l}10 / 20 \\
(50 \%)\end{array}$ & $\begin{array}{l}18 / 20 \\
(90 \%)\end{array}$ \\
\hline AAA61276.1 & Homo sapiens & $\mathrm{Kv}$ & 35 & 0.24 & $\begin{array}{l}16 / 43 \\
(37 \%)\end{array}$ & $\begin{array}{l}25 / 43 \\
(58 \%)\end{array}$ \\
\hline NP_002223.3 & Homo sapiens & $\mathrm{K} v 1.3$ & 35.0 & 0.17 & $\begin{array}{l}20 / 58 \\
(34 \%)\end{array}$ & $\begin{array}{l}32 / 58 \\
(55 \%)\end{array}$ \\
\hline CDS30290.1 & Hymenolepis microstoma & $\mathrm{Kv}$ & 32.7 & 2.4 & $\begin{array}{l}22 / 80 \\
(28 \%)\end{array}$ & $\begin{array}{l}40 / 80 \\
(50 \%)\end{array}$ \\
\hline AE096823.2 & Lateolabrax japonicus & $\mathrm{K} v 1.3$ & 33.1 & 0.56 & $\begin{array}{l}18 / 45 \\
(40 \%)\end{array}$ & $\begin{array}{l}26 / 45 \\
(58 \%)\end{array}$ \\
\hline CCQ21618.1 & Listeria monocytogenes & $\mathrm{Kv}$ & 36 & 0.012 & $\begin{array}{l}14 / 41 \\
(34 \%)\end{array}$ & $\begin{array}{l}27 / 41 \\
(66 \%)\end{array}$ \\
\hline NP_001245037.1 & Macaca mulatta & Kv1.3 & 35.0 & 0.18 & $\begin{array}{l}20 / 58 \\
(34 \%)\end{array}$ & $\begin{array}{l}32 / 58 \\
(55 \%)\end{array}$ \\
\hline NP_032444.2 & Mus musculus & Kv1.3 & 33.5 & 0.47 & $\begin{array}{l}14 / 38 \\
(37 \%)\end{array}$ & $\begin{array}{l}24 / 38 \\
(63 \%)\end{array}$ \\
\hline XP_007383667.1 & Punctularia strigosozonata & $\mathrm{Kv}$ & 44 & $5 e-04$ & $\begin{array}{l}33 / 105 \\
(31 \%)\end{array}$ & $\begin{array}{l}53 / 105 \\
(50 \%)\end{array}$ \\
\hline WP_006887331.1 & Rothia aeria & $\mathrm{Kv}$ & 36.6 & 0.032 & $\begin{array}{l}17 / 67 \\
(25 \%)\end{array}$ & $\begin{array}{l}34 / 67 \\
(51 \%)\end{array}$ \\
\hline NP_707157.2 & Shigella flexneri 2a str. 301 & $\mathrm{Kv}$ & 29 & 5.3 & $\begin{array}{l}18 / 66 \\
(27 \%)\end{array}$ & $\begin{array}{l}36 / 66 \\
(55 \%)\end{array}$ \\
\hline CAA56175.1 & Solanum tuberosum & Kir & 32.0 & 1.9 & $\begin{array}{l}18 / 67 \\
(27 \%)\end{array}$ & $\begin{array}{l}34 / 67 \\
(51 \%)\end{array}$ \\
\hline NP_631700.1 & Streptomyces coelicolor & $\mathrm{Kv}$ & 30 & 0.54 & $\begin{array}{l}9 / 34 \\
(26 \%)\end{array}$ & $\begin{array}{l}24 / 34 \\
(71 \%)\end{array}$ \\
\hline CDW52461.1 & Trichuris trichiura & $\mathrm{Kv}$ & 31.6 & 1.9 & $\begin{array}{l}12 / 49 \\
(24 \%)\end{array}$ & $\begin{array}{l}27 / 49 \\
(55 \%)\end{array}$ \\
\hline WP_033004452.1 & Vibrio azureus & $\mathrm{Kv}$ & 31.6 & 1.3 & $\begin{array}{l}27 / 91 \\
(30 \%)\end{array}$ & $\begin{array}{l}46 / 91 \\
(51 \%)\end{array}$ \\
\hline
\end{tabular}


Table 2 (on next page)

Physicochemical characterization of GiK by Protparam . 


\begin{tabular}{|l|l|}
\hline Number of amino acids & $\mathbf{1 4 1 6}$ \\
\hline Molecular weight & 25811.2 \\
\hline Instability index & 45.47 \\
\hline Aliphatic index & 93.28 \\
\hline $\begin{array}{l}\text { Grand average of hydropathicity } \\
\text { (Gravy) }\end{array}$ & -0.053 \\
\hline Isoelectric point & 8.18 \\
\hline Ext. Coeficiente & 141880 \\
\hline
\end{tabular}

1 
Table $\mathbf{3}$ (on next page)

Prediction of highly conserved residues from GiK. 


\begin{tabular}{|c|c|c|c|c|}
\hline Domain or motif & Description & $\begin{array}{l}\text { Accession } \\
\text { number }\end{array}$ & $\begin{array}{l}\text { Position (E } \\
\text { value) }\end{array}$ & Server \\
\hline Ion_trans_2 & $\begin{array}{l}\text { Ionic channel. This family includes } \\
\text { the two membrane helix type ion } \\
\text { channels found in bacteria. }\end{array}$ & pfam07885 & $\begin{array}{l}168-245 \\
(1.35 \mathrm{e}-08)\end{array}$ & $\begin{array}{l}\text { NCBI Conserved } \\
\text { domains, Motif Search, } \\
\text { InterProScan tool }\end{array}$ \\
\hline 227696 & $\begin{array}{l}\text { EXS domain-containing protein } \\
\text { [Signal transduction } \\
\text { mechanisms]. }\end{array}$ & COG5409 & $\begin{array}{l}12-170 \\
(0.44)\end{array}$ & $\begin{array}{l}\text { ExPASy PROSITE, } \\
\text { Motif Search }\end{array}$ \\
\hline 215625 & $\begin{array}{l}\text { Voltage-dependent potassium } \\
\text { channel; Provisional. }\end{array}$ & PLN03192 & $\begin{array}{l}181-242 \\
(0.14)\end{array}$ & $\begin{array}{l}\text { ExPASy PROSITE, } \\
\text { Motif Search }\end{array}$ \\
\hline 236711 & $\begin{array}{l}\text { Voltage-gated potassium channel; } \\
\text { Provisional. }\end{array}$ & PRK10537 & $\begin{array}{l}196-214 \\
(0.70)\end{array}$ & $\begin{array}{l}\text { ExPASy PROSITE, } \\
\text { Motif Search }\end{array}$ \\
\hline 2POREKCHANEL & Potassium channel domain & PR01333 & $\begin{array}{l}202-230 \\
(0.00032)\end{array}$ & Block Searcher \\
\hline EAGCHANLFMLY & $\begin{array}{l}\text { EAG/ELK/ERG potassium } \\
\text { channel family signature }\end{array}$ & PR01463 & $\begin{array}{l}193-210 \\
(0.029)\end{array}$ & Block Searcher \\
\hline KCHANNEL & Potassium channel signature & PR00169 & $\begin{array}{l}190-212 \\
(0.1)\end{array}$ & Block Searcher \\
\hline
\end{tabular}




\section{Table 4(on next page)}

Validation scores from RAMPAGE, QMEAN, ProSA-web, ERRAT and Verify 3D of the constructed models. 
1

\begin{tabular}{|c|c|c|c|c|c|c|c|c|}
\hline Software & $\begin{array}{l}\text { Templete } \\
\text { (PDB ID) }\end{array}$ & $\begin{array}{l}\text { Ramachandran } \\
(\%)\end{array}$ & $\begin{array}{l}\text { QMEAN } \\
\text { score }\end{array}$ & $\begin{array}{l}\text { Z- } \\
\text { score }\end{array}$ & $\begin{array}{l}\text { ERRAT } \\
\text { score }\end{array}$ & $\begin{array}{l}\text { Verify } \\
\text { 3D }\end{array}$ & Residues & $\operatorname{RMSD}(\AA)$ \\
\hline \multirow[t]{4}{*}{ Modeller } & 5TJ6 & 90.4 & 0.141 & -7.56 & 44.26 & 26.28 & 500 & 4.28 \\
\hline & $5 \cup 70$ & 90.0 & 0.094 & -8.09 & 39.62 & 14.06 & 500 & 5.05 \\
\hline & 5TJI & 94.2 & 0.296 & -5.07 & 69.24 & 35.60 & 500 & 3.90 \\
\hline & $5 \cup 76$ & 88.4 & 0.023 & -9.22 & 34.97 & 26.28 & 500 & 4.46 \\
\hline Raptorx & 5TJ6 & 89.8 & 0.191 & -6.92 & 56.64 & 20.60 & 500 & 4.85 \\
\hline \multirow[t]{2}{*}{ I-tasser } & $5 \mathrm{TJ} 6$ & 72.9 & 0.101 & -8.78 & 86.58 & 38.80 & 500 & 3.97 \\
\hline & $5 \cup 70$ & 69.6 & 0.089 & -9.12 & 81.91 & 44.60 & 500 & 5.01 \\
\hline \multirow{4}{*}{$\begin{array}{l}\text { Swiss } \\
\text { model }\end{array}$} & $5 T J 6$ & 89.8 & 0.205 & -6.21 & 81.48 & 33.00 & 296 & 0.92 \\
\hline & $5 \cup 70$ & 92.8 & 0.271 & -5.53 & 87.54 & 39.38 & 292 & 0.91 \\
\hline & 5TJI & 92.5 & 0.240 & -5.82 & 88.57 & 30.98 & 296 & 1.12 \\
\hline & $5 \cup 76$ & 92.9 & 0.191 & -6.34 & 84.17 & 26.35 & 297 & 1.17 \\
\hline \multirow[t]{2}{*}{ Phyre2 } & $5 \mathrm{TJ} 6$ & 95.7 & 0.239 & -5.72 & 61.63 & 37.36 & 265 & 1.01 \\
\hline & $5 \cup 76$ & 94.7 & 0.251 & -5.99 & 35.04 & 38.44 & 372 & 1.10 \\
\hline
\end{tabular}

2 


\section{Table 5 (on next page)}

Best docking score values $(\mathrm{kcal} / \mathrm{mol})$ from the potassium channel blockers to 3D-GiK model. 


\begin{tabular}{|c|c|c|c|c|c|}
\hline Compound & $\begin{array}{l}\text { Docking } \\
\text { score } \\
\text { (kcal/mol) }\end{array}$ & Compound & $\begin{array}{l}\text { Docking } \\
\text { score } \\
\text { (kcal/mol) }\end{array}$ & Compound & $\begin{array}{l}\text { Docking } \\
\text { score } \\
\text { (kcal/mol) }\end{array}$ \\
\hline UCL_1684 & -11.2 & ZINC13489790 & -8 & Flecainide & -6.9 \\
\hline ZINC38144725 & -10.8 & Imipramine & -7.9 & Mepivacaine & -6.9 \\
\hline Terfenadine & -10.6 & Trifluoroperazine & -7.9 & ZINC13489786 & -6.8 \\
\hline ZINC00018512 & -10.4 & ZINC13489791 & -7.9 & ZINC13760202 & -6.8 \\
\hline ZINC00598948 & -10.1 & ZINC13489800 & -7.9 & $\begin{array}{l}\text { ZINC13777065 } \\
\text { 1-Ethyl-2- }\end{array}$ & -6.8 \\
\hline Bicuculine & -10 & ZINC13489804 & -7.9 & Benzimidazolinone & -6.7 \\
\hline Cromoglicic acid & -10 & ZINC13489830 & -7.9 & ZINC13760207 & -6.7 \\
\hline Penitrem_A & -10 & ZINC13760212 & -7.9 & ZINC13760214 & -6.7 \\
\hline BMS_204352 & -9.4 & Linopirdine & -7.8 & ZINC03935230 & -6.5 \\
\hline NS1643 & -9.1 & ZINC13442157 & -7.8 & ZINC13557606 & -6.5 \\
\hline Paxilline & -9.1 & ZINC13489810 & -7.8 & ZINC13777062 & -6.5 \\
\hline CP_339818 & -9 & ZINC13489818 & -7.8 & ZINC27617403 & -6.5 \\
\hline Tubocurarine & -8.9 & ZINC13489829 & -7.8 & Dofetilide & -6.4 \\
\hline ZINC13489797 & -8.8 & ZINC13489785 & -7.7 & Retigabine & -6.4 \\
\hline UK_78282 & -8.7 & TRAM_34 & -7.6 & ZINC00005768 & -6.4 \\
\hline Verruculogen & -8.7 & ZINC13489794 & -7.6 & ZINC13760203 & -6.4 \\
\hline ZINC13489806 & -8.6 & ZINC13489798 & -7.6 & ZINC13777063 & -6.4 \\
\hline ZINC13644028 & -8.6 & ZINC13489784 & -7.5 & ZINC13777067 & -6.4 \\
\hline DIDS & -8.5 & ZINC13489803 & -7.5 & Correolide & -6.3 \\
\hline ZINC01535217 & -8.5 & ZINC13489813 & -7.5 & ZINC03935234 & -6.3 \\
\hline ZINC13442159 & -8.5 & ZINC13557604 & -7.5 & ZINC03935235 & -6.3 \\
\hline $\begin{array}{l}\text { ZINC38144724 } \\
\text { Bicuculine }\end{array}$ & -8.5 & Amitriptyline & -7.4 & ZINC03946466 & -6.3 \\
\hline methiodide & -8.4 & Dequalinium & -7.4 & ZINC13777069 & -6.3 \\
\hline ZINC13489814 & -8.4 & ZINC01539875 & -7.4 & ZINC13777072 & -6.3 \\
\hline ZINC13489817 & -8.4 & ZINC13489789 & -7.4 & Procaine & -6.2 \\
\hline ZINC00015850 & -8.3 & Quinidine & -7.3 & Zoxazolamine & -6.1 \\
\hline ZINC00603820 & -8.3 & ZINC00014006 & -7.3 & ZINC13777058 & -6 \\
\hline ZINC01539867 & -8.2 & ZINC01535218 & -7.3 & ZINC18096411 & -6 \\
\hline ZINC13489795 & -8.2 & ZINC13760206 & -7.3 & ZINC13777075 & -5.8 \\
\hline ZINC13489796 & -8.2 & ZINC27617400 & -7.3 & ZINC13643922 & -5.7 \\
\hline ZINC13489807 & -8.2 & Psora_4 & -7.2 & Chlorzoxazone & -5.5 \\
\hline ZINC13489823 & -8.2 & ZINC18189761 & -7.2 & ZINC13579814 & -5.5 \\
\hline ZINC29309163 & -8.2 & Pimaric_acid & -7.1 & LY_97241 & -5 \\
\hline Niguldipine & -8.1 & Miconazole & -7 & Clofilium & -4.8 \\
\hline ZINC13489799 & -8.1 & ZINC13760204 & -7 & Halothane & -4.5 \\
\hline XE991 & -8 & ZINC13760205 & -7 & 4_Aminopyridine & -4.4 \\
\hline ZINC01539870 & -8 & ZINC13760213 & -7 & & \\
\hline
\end{tabular}




\section{Table 6(on next page)}

Binding sites from the potassium channel blockers to GiK. 


\begin{tabular}{|c|c|c|}
\hline Region & Amino acid residues & Potassium channel blockers \\
\hline$T$ & $\begin{array}{l}\text { Phe218, Val221, } \text { Val222, } \text { Leu225, } \\
\text { Tyr226, Leu250, Leu278, Ile279, } \\
\text { lle456, Arg457, Asp488, Val489, } \\
\text { Phe490 }\end{array}$ & $\begin{array}{l}\text { UCL_1684, terfenadine, cromoglicic acid, CP_339818, } \\
\text { niguldipine, imipramine, Psora_4, mepivacaine, procaine, } \\
\text { chlorzoxazone, 4_Aminopyridine }\end{array}$ \\
\hline II & $\begin{array}{l}\text { Leu65, Gly113, Gln116, Leu117, } \\
\text { Tyr120, Met122, Phe125, Ile127, } \\
\text { Arg129 }\end{array}$ & $\begin{array}{l}\text { Bicuculine, Penitrem_A, BMS_204352, NS1643, paxilline, } \\
\text { tubocurarine, UK_78282, DIDS, bicuculine methiodide, } \\
\text { trifluoroperazine, amitriptyline, dequalinium, miconazole, } \\
\text { flecainide, 1-Ethyl-2-Benzimidazolinone, correolide, } \\
\text { clofilium, halothane }\end{array}$ \\
\hline III & $\begin{array}{l}\text { Val344, Leu345, Ser346, Val377, } \\
\text { Thr379, Gly383, Arg384, Leu388, } \\
\text { Leu414, Ala415, Phe418, Pro419 }\end{array}$ & $\begin{array}{l}\text { Verruculogen, XE991, linopirdine,TRAM_34, quinidine, } \\
\text { pimaric_acid, dofetilide, retigabine, zoxazolamine ,LY_97241 }\end{array}$ \\
\hline
\end{tabular}

